\title{
Effects of treatment of pre-weaned dairy calves with recombinant bovine somatotropin on somatotropic axis and immune parameters
}

Anna Luiza Belli de Souza Alves Costa*,Anderson Veronese, Kelly Flanagan, Rafael Moreira, Ronaldo Braga Reis, Sandra Gesteira Coelho, Rodrigo Melo Meneses, Ricardo Carbonari Chebel

Departamento de Zootecnia, Escola de Veterinária, Universidade Federal de Minas Gerais (UFMG), Belo Horizonte, MG, Brazil

*Corresponding author

e-mail: annabelliac@gmail.com

\begin{abstract}
The weaning event represents great challenge for dairy calves and might cause negative effects on their immune system. The growth hormone (GH) and the Insulin like growth factor type 1 (IFG-1) have the ability to improve immunological cells activities in humans and rodents. Strategies of bST treatment were already studied around the transition period of dairy cows, with divergent but interesting results on these animal's immunity. The aim of the present study was to investigate the effects of treatment with recombinant bovine somatotropin (bST) on the somatotropic axis and on selected immune parameters of dairy calves. Therefore, 36 dairy female calves were randomly assigned to one of two treatments: Control = Saline $(0,9 \%)$; bST $=1.5$ to $1.8 \mathrm{mg} / \mathrm{Kg}$ of bST. Treatments were performed every 7 days, from 21 to 63 days of life; 8 blood and plasma samples were collected from each animal during the experimental phase for posterior analyses. bST treatment increased GH $(\mathrm{P}<0.01)$ and IGF-1 (P < 0.01) concentrations, while insulin and glucose were not different among groups. E. coli was used to access neutrophil phagocytosis $(\mathrm{P}=0.74)$ and oxidative burst $(\mathrm{P}=0.71)$, but no differences were encountered between treatments. We found a tendency for bST to affect median florescence intensity expression of CD62L on granulocytes $(\mathrm{P}=0.06)$ and lymphocytes $(\mathrm{P}=0.13)$, but only on lymphocytes for CD18 ( $\mathrm{P}=0.07)$. Haptoglobin levels were different between groups only on day $3(\mathrm{P}<0.04)$ after animals were weaned. Non-esterified fatty acids (NEFA), beta hydroxybutirate (BHBA), glucose, body weight, wither height and average daily gain (ADG) did not differ between treatments. Although, daily milk replacer intake was higher for animals in the Control group $(\mathrm{P}<0.02)$. Data of concentrate consumption was not possible to be collected. It would explain if animals of the bST group ate more concentrate to achieve the same body weight as Control group, or if they were more efficient in using diet nutrients. Cortisol produced around calving and weaning might have contributed for the decrease in the evaluated immune parameters levels, but it was not analyzed. Despite the gradual weaning, until the complete weaning at 49 days of life,
\end{abstract}


the event itself seemed to have a negative impact on the immunological system. The somatotropic axis and metabolic analyses lead us to believe that these dairy calves were facing a period of negative energy balance, with the uncoupling of the somatotropic axis. We believe that the chosen treatment strategy is not enough to prevent disease incidence. 